\title{
How Family Ties Affect Underground Economy Tax Morale and Trust
}

\author{
Mauro Marè, Antonello Motroni, Francesco Porcelli
}

January 2020

\begin{abstract}
This paper reports empirical evidence supporting the hypothesis that family ties should be considered among the main determinants of tax morale, underground economy and trust. In societies where the power of the family is very high, the quality of public institutions tends to be low. This connection shapes the behavior of taxpayers and tends to increase the underground economy. The econometric analysis is based on linear panel data models and a new original dataset that puts together data on personal values, social capital and tax morale, in combination with an index of the shadow economy. The final results show that in countries where family ties are stronger, the level of trust and tax morale is low, while underground economy is higher.
\end{abstract}

Keywords: family ties, tax evasion, trust, panel data

JEL Classifications: H26, D73, J12

We thank Alberto Alesina, Denvil Duncan, Friedrich Schneider, and Joel Slemrod for comments. We also thank the participants of the Bocconi University Seminar on "Tax evasion and Economy", 2013 European Public Choice Society in Zurich, 2013 International Institute of Public Finance Conference in Taormina, and the $28^{\text {th }}$ Annual Congress of the EEA/ESEM in Gothenburg for useful suggestions. The usual caveat applies. 
People who do not trust one another will end up cooperating only under a system of formal rules and regulations, which have to be negotiated, agreed to, litigated, and enforced, sometimes by coercive means. This legal apparatus, serving as a substitute for trust, entails what economists call "transaction costs." Widespread distrust in a society, in other words, imposes a kind of tax on all forms of economic activity, a tax that high-trust societies do not have to pay.

Francis Fukuyama, Trust,1995.

"The first source of power is the family. (...) Scholars have always recognized the Italian family as the only fundamental institution in the country, a spontaneous creation of the national genius, adapted through the centuries to changing conditions, the real foundation of whichever social order prevails. In fact, the law, the State and society function only if they do not directly interfere with the family's supreme interests."

Luigi Barzini, The Italians, 1964. 


\section{Introduction}

Over the last decade, a growing part of the economic literature on tax evasion has extensively approached individual decisions to comply with tax obligations by exploring the role of trust and taxpayers' ethics, providing robust evidence that tax morale and quality of institutions are important factors in explaining the behavior of taxpayers and the size of the underground economy in a given country.

This paper contributes to this literature by providing empirical evidence of a positive relationship between the strength of family ties and the level of the shadow economy and a negative one with trust and tax morale. In particular, we construct a bridge between two fields of literature. First, the literature on family ties and social capital, which suggests that the strength of family ties is negatively correlated with the quality of social capital, trust in public institutions, political participation, and economic outcomes (see, among the others, Banfield (1958), Fukuyama (1995), Putnam (1993), Bisin and Verdier (1998, 2000, 2010), Alesina and Giuliano (2010, 2011), Guiso et al., 2006, 2007, 2010). Second, the literature on tax morale and tax evasion which shows that the level of tax evasion is higher where the level of tax morale and citizens' ethics is lower (see, among others, for example, Torgler and Schneider (2006, 2009), Torgler (2003, 2004, 2005, 2006, 2007), Alm and Torgler (2006), Feld and Torgler (2007), Frey and Torgler (2007), Lago Penas and Lago Penas (2010), Alm et al. (2006), Alm and Martinez-Vasquez (2007)).

We believe that family ties are an important cause of the underground economy and tax evasion because they affect the degree of tax morale. In societies where the power of the family is very high, the quality of public institutions is low; this strongly affects the civic values of taxpayers, and therefore shapes their compliance behavior and tends to increase the underground economy.

Our empirical strategy is to use linear panel data models to estimate the relationship between the strength of family ties and the degree of the underground economy. Therefore, we construct a new original dataset that combines data on personal values, social capital, and tax morale, with an index of the shadow economy. Variables related to personal values are based on different waves of the World Value Survey and European Value Survey, which cover more than 70 countries over almost 20 years, spanning from 1990 to 2010. Data on the underground economy are extracted from Schneider and Enste (2000, 2002), Schneider (2005), Schneider et al. (2010), and in particular Medina and Schneider (2017). In addition, as control variables, we also use data on religion, importance of politics and political orientation.

To interpret the correlation between family ties and the underground economy, in terms of the causal relationship, we also perform an instrumental variables exercise, using the variables that measure the importance of the role of the mother and the role of the father in the family, which were registered in the 1981 European Value Survey, as an instrument for the variables used to measure the strength of family ties. In general, the power of the family seems to depend strongly on the 'role of the mother' within the family. The different roles of the father and the mother within any family should largely explain the 'familial mentality,' which gives rise to weak collective responsibilities, low civic involvements and tax morale (see on this Gambino (1998, 39-50), Simone (2005), Turiello (1887), Bachofen (1949)).

Our econometric analysis provides three key findings. First, we provide the first empirical evidence supporting a causal relationship between family ties and the dimension of the underground 
economy (i.e., where family ties are stronger, the degree of the underground economy is higher). Second, we provide empirical evidence of a negative relationship between family ties, tax morale and trust. Third, we confirm that there is also a relationship between the strength of family ties and some other control variables - such as religion, the importance of politics and the political orientation - shown in the online appendix.

Our analysis does not imply any moral judgment on family values; on the contrary, we are aware that family, in many contexts, is a crucial positive factor for economic progress and good life. Our point is very simple: it is important to assess the balance between trust in the family and trust in public institutions. If people use mainly their family to have a relationship with their peers, then the degree of trust is affected, as well as the quality of public institutions and participation in collective life. As a result, one of the main policy implications of our results is that the structure of society (and the role of the family) is one of the main factors that should be taken into account when designing policies with the aim of reducing the underground economy and tax evasion.

The rest of the paper is organized into the following sections. In section 2, we briefly review the recent theory of tax evasion and underground economy and discuss the main results of the literature on this matter. In section 3, we consider recent works on tax morale and evasion. In section 4, we address the role of the family in transmitting cultural traits and social values and the power of the family in affecting tax morale, underground economy and trust. In section 5 , we define the structure of the dataset and we describe the main variables. In section 6 , we present the empirical and the econometric approach that we use to assess the role of the family and social capital on the underground economy, trust and tax morale, and we describe and comment the main results obtained from our empirical estimates. Finally, in section 7 , we present some short conclusions and potential directions for further research. Additional tables and figures are reported in the online Appendix.

\section{Tax Evasion and the Underground Economy}

Tax evasion has been widely investigated over the last four decades. Most analyses focus on the pioneeristic approach of Allingham and Sandmo (1972), which look at tax evasion as a problem of portfolio choice; essentially, taxpayers will eventually decide to not comply if they estimate a possible monetary gain from cheating behaviour.

Some studies have however shown that the role of tax inspection and the measures of deterrence in fighting evasion are far from being clear, and are often disputed: "fines and tax auditing are unable to explain the actual level of tax compliance as they are too low to provide effective deterrence in most OECD countries." ${ }^{1}$ Other authors even suggest that the real enigma is not why tax fines and inspections are so unsuccessful in fighting tax evasion, rather than why do people pay taxes honestly, given the rather low level of fines, intensity of controls, and the low probability of being caught ${ }^{2}$. More generally, the empirical evidence on the impact of tax auditing and fines on tax evasion and the shadow economy remains ambiguous. ${ }^{3}$

\footnotetext{
${ }^{1}$ See, among others, Slemrod-Yitzhaki (2002), Torgler (2003), Braithwaite-Wenzel (2008), Feld-Schmidt-Scnheider (2007).

2 See Alm-McClelland-Schulze (1992).

${ }^{3}$ Feld- Schmidt-Schenider (2007).
} 
Over the last decade, some papers have tried to assess the role of tax morale in explaining the underground economy. Alm and Torgler (2004), Alm and Martin-Vasquez (2007), Alm and Gomez (2008), Alm and Torgler (2012), Alm and McClellan (2012), Alm et al. (2016) and Alm and Liu (2018), and some other authors ${ }^{4}$ have estimated that tax morale plays quite a significant role in determining taxpayers' behavior and their decision for tax evasion. In the same way, some recent papers by Williams and Horodnic (2016) and Williams and Krasniqi (2017), by using an institutionalist approach (and not a rational economic one) did find a clear strong (negative) role of tax morale on the underground economy (when tax morale is higher, the undeclared economy is lower).

The main argument is that, together with the standard variables (such as economic growth, the level of education, tax pressure, the level and quality of public expenditure, the policy of prosecution and punishment, etc.), a better understanding of the shadow economy also requires to investigate other variables, such as "subjective perception, expectations, attitudes and motivations, tax morale or perceived institutional quality." ${ }^{5}$ Even if the main structural factors remain fundamental, data and some recent models suggest that it is necessary to extend the analysis to include moral dimension and ethics: "the violation of social norms is connected with higher costs of being active in the informal sector. Similarly, better institutions provide stronger incentives to behave legally and increase the cost of illegal activities as a consequence of greater institutional accountability." ${ }^{16}$ Therefore, to explain international differences in the size of the underground economy, it is also desirable to focus on individual morale, social norms, and public ethics ${ }^{7}$.

Many papers have investigated whether differences in tax morale across countries tends to reflect considerable variations in the shadow economy. Alm and Torgler (2006) addressed the case of Europe and the USA, and found a strong negative correlation between the two variables. Alm et al. (2006) investigated transition countries and obtained the same result: countries with low tax morale show a larger shadow economy. Torgler and Schneider (2009) considered a large number of countries and found evidence that a higher degree of a nation's tax morale reduces the size of the shadow economy in that country. Alm and Martinez-Vasquez (2007) and Torgler (2005) investigated the role of tax morale in Latin America and found that it was related to the size of the shadow economy. Torgler (2004) investigated the case of Asian Countries and found that trust in the government and the legal system have a positive effect on tax morale; therefore, implying that this should reduce the size of the shadow economy, and the same is being confirmed by Torgler (2007). Alm et al. (2016) found evidence that the impact of confidentiality of taxpayer information is crucial in explaining the differences in tax evasion in the Us and Italy - public disclosure acts as an additional deterrent to tax evaders. Finally, Williams and Krasniqi (2017) and Williams and Horodnic (2016) found clear and strong evidences of the importance of tax morale when tackling tax non-compliance in the European Union and Eurasian countries - a strong negative correlation between tax morale and tax evasion.

\footnotetext{
${ }^{4}$ See among others, Torgler-Schneider (2006, 2009), Torgler (2003, 2004, 2005, 2006, 2007), Alm-Torgler (2006), FeldTorgler (2007), Frey-Torgler (2007), Lago-Penas-Lago-Penas (2010), Lewis-Carrera-Cullis-Jones (2009),TsakumisCuratola-Porcano (2007), Alm-Martinez-Vasquez-Torgler (2006), , Halla (2010), Konig-Schuknecht (2018).

${ }^{5}$ See Torgler-Schneider (2009).

${ }^{6}$ Torgler-Schneider (2009).

${ }^{7}$ See also the recent papers by Williams-Horodnic (2016) and Williams-Krasniqi (2017).
} 
The role of tax morale is important in relation to both tax structure and public spending. In a recent paper, Barone and Mocetti (2011) investigated the determinant of tax morale at the municipal level in Italy. The authors showed that inefficiency in public expenditure (negatively) shapes individual tax morale; in particular, that at the level of Italian municipalities, where public spending is more inefficient, tax morale is lower, even when the authors did not use the EVS (European Value Survey) and WVS (World Value Survey), but the Survey on Household Income and wealth of the Bank of Italy. Therefore, even with a different data set, the relationship between tax morale and the main characteristics of the public sector is largely confirmed. The implication is that an efficient public service provision may promote a "cooperative reaction of taxpayers in the form of a better attitude toward fiscal duties."

The evidence and econometric estimates show that in most specifications, tax morale is highly significant in explaining the size of the shadow economy and the rate of tax compliance. Furthermore, in some areas and regions of the world, tax cheating may be essentially attributed to taxpayers' tax morale.

\section{The Role and the Importance of Tax Morale}

At this point, it is worth considering the possible determinants of tax morale. As we have already mentioned above, in the portfolio traditional approach to tax evasion, the social and ethics factors such as tax morale and trust have been largely neglected. A recent bulk of literature ${ }^{8}$ on $\operatorname{tax}$ evasion have instead emphasized that tax compliance - and in particular non-compliance - cannot be adequately explained only with the traditional economic approach, but it requires also to consider other social and moral factors, such as taxpayers' ethics, tax morale and the level of trust and social capital.

Following Torgler and Schneider (2007), we can define "tax morale" as the moral obligation (or the intrinsic motivation) to pay taxes. This obviously stems not from people economic (portfolio) calculations, but essentially from other social and cultural factors of population, which have accumulated by historical traditions, the role of religion, the sense of the community, the social capital, the quality of political institutions, the development of democracy, the level of corruption and the quality of education. Tax evasion and underground economy are very complex, multidimensional phenomena, which requires a multi factors approach.

Lago Penas and Lago Penas (2010) show that tax morale in European countries varies regularly with socio-demographic characteristics, personal financial experiences, political attitudes, and regional GDP, in addition to some ethnic and linguistic fractionalizations. Torgler (2006) also addresses the role of religion in shaping moral value and tax morale and, therefore, tax evasion. By using a weighted ordered probit model, he finds that religiosity and tax morale are positively correlated, even though this effect tends to vary somewhat for sub-groups of religion, such as Catholic, Protestant, Jewish, Hindu, Moslem, and Buddhist. However, these results should be accepted with caution, given some difficulties with the data.

\footnotetext{
${ }^{8}$ See Alm and Martinez-Vasquez (2007), Alm and Torgler (2004), Alm and Torgler (2012), Alm et al (2016) and also the recent useful accounts made by Williams and Krasniqi (2017), Williams and Horodnic (2016) and Horodnic (2018).
} 
In a very interesting recent paper Horodnic (2018) addresses the main factors that shapes tax morale and their importance to explain tax compliance and non-tax compliance. If one wants to define a fully-fledged approach to address the underground economy and tax evasion, apart from pecuniary factors, such as the strategy and probability of detention and the size of the fines, one has also to consider non-pecuniary factors of tax compliance, such as tax morale, the social capital, the degree of generalized trust and some other important variables.

Among these other variables that explain tax morale there are ${ }^{9}$ a) historical factors, traditions and heritage that tend to matter when shaping public ethics and tax morale; b) demographic and ethnic status; c) the importance of religion; in general, religiosity is positively correlated with tax morale; d) the degree of trust - trust in the government, in the parliament, in the legal system, in politicians, police and political parties; e) the quality of government spending; $f$ ) the degree of fairness of the tax system; $g$ ) the income inequality; $h$ ) the level of corruption; i) the culture; j) the perception of tax fraud; k) gender and age - women and older people have higher tax morale; I) the level of education - people better educated show a higher tax morale.

Summarizing the main results, in general, tax morale tends to rise with age, is lower for the selfemployed and unemployed, for upper-class individuals, and is also positively correlated with education. National pride increases tax morale. Tax morale is stronger for students and retired people, for women and married people, but weaker for individuals living together, whereas financial satisfaction increases tax morale. Trustworthiness increases tax morale, while perceived corruption strongly reduces it. Finally, religiosity tends to increase tax morale; however, this aspect is quite controversial.

\section{Family Ties, the Power of the Family and the Transmission of Social Values}

An important recent stream of research - see among others, Bisin and Topa (2002), Bisin and Verdier $(1998,2000,2010)$ - has instead emphasized the models of cultural transmission, in particular the transmission of social status and cultural traits; but the same should apply also for tax morale. Starting from the economic models of interdependence of preferences, some authors argued that "children are born naïve, with not well-defined preferences and cultural traits. They acquire preferences through observation, imitation and adoption of cultural models with which they are matched. Children are first matched with their family ('vertical transmission'), and then with the population at large, e.g. teachers, role models, etc. ('oblique transmission'). In other words, parents purposefully attempt at socializing their children to a particular trait. (...) but parents can perceive welfare of their children only through the filter of their own (the parents') preferences. This particular form of myopia ('imperfect empathy') is quite crucial."

Along this line, therefore, one may assume that cultural traits, moral values, and social capital (e.g., trust in institutions) may be essentially transmitted (although not exclusively) by families to their heirs, and that, within a certain equilibrium, these values tend to remain stable, at least within a given span of time. In fact, the persistence of moral values, the degree of civicness, and social capital in most of developed countries, and in particular in some Italian regions, as first proved by Putnam to extend across least six centuries, should confirm the stability of moral value within the members of various families, and in some specific social and economic context. Family matters

${ }^{9}$ On this approach, see also the papers of Williams and Horodnic (2016) and Williams and Krasniqi (2017). 
and matters a lot. Family shapes the moral values of individual members; in particular, the cultural traits of the youngest, in the end, affect public ethics and tax morale. Therefore, the transmission of cultural values within the same family along different periods of time would also inevitably imply some, more or less pronounced, stability of public morale, social capital, and trustworthiness. We might imagine the existence of different multiple equilibria, some positive, some negative, and a clear difficulty to shift from one to another.

Of course, apart from vertical transmission, there is also some, more or less intense, form of oblique transmission, where the social context (e.g., school, neighborly-ness, etc.) helps to share moral values. In general, we observe strong homogeneity among the various communities, and people's choice to reside in areas where other individuals live that share the same values. We also observe a strong persistence of cultural traits, attitudes, values, and lifestyles among various communities, with some pronounced resilience of cultural traits and heterogeneous values. For example, Orthodox Jewish communities in the United States, but also elsewhere in the world, are a clear example of culture persistence. Outside the US, we have the well-known case of Corsicans, Catalans, Irish Catholics, and Italians, especially in Northern Europe (see Bisin-Verdier, 2010).

Moreover, in some recent works, Guiso et al. (2006, 2007, 2010) and Butler et al. (2009) show that in Italy social capital tends to persist over the long-term (more than five centuries) and explains its stability since the experience of free-city-state in the Middle Age. With a different approach based on instrumental variables, Tabellini $(2008,2010)$ links cross-country variation in measures of trust to the quality of political institutions in the nineteenth century and, therefore, following the seminal works of Banfield (1958) and Putnam (1993), attributes the persistence of institutions to indicators of individual values and beliefs, such as trust and respect for others. Along the same line, some recent literature proves the long-term persistence and long lasting effects of institutions on socio-economic outcomes ${ }^{10}$. Of course, the finding of some significant and robust statistical correlations does not imply casual relationships and endogeneity needs to be addressed.

The first author who clearly described the importance of family ties was Edward Banfield in $1958^{11}$, as a consequence of his research in the South of Italy. The author depicts family as "amoral familism", a situation in which there is "inability of the villagers to act together for their common good or, indeed, for any end transcending the immediate, material interest of the nuclear family. This inability to concert activity beyond the immediate family arises from an ethos - that of 'amoral familism (...) (according to which people) maximize the material, short run advantage of the nuclear family; and assume that all others will do likewise" (p. 9).

Therefore, "in a society of amoral familists, no one will further the interest of the group or community except as it is to his private advantage to do so" (p. 83). In this society, it is very difficult to build and maintain public organizations given the selfish attitude of individuals who rely exclusively on family. "The inducements which lead people to contribute their activity to organizations are to an important degree unselfish (e.g., identification with the purpose of the organization) and they are often non-material. Moreover, it is a condition of successful organization that members have some trust in each other and some loyalty to the organization".

10 See Bisin and Verdier (2010) and Acemoglu and Robinson (2011), North (1990) La Porta-Lopez de Silanes et al. (1997).

${ }^{11}$ Banfield (1958). 
This aspect is not new, unique, or so surprising, since in many other countries and among other people ${ }^{12}$, "where legal authority is weak and the law is resented and resisted, the safety and welfare of the individual are mainly assured by the family." This characteristic of family ties is the key core of Italian society but is also a general characteristic of many other countries in Southern Europe ${ }^{13}$ and Asia, and has attracted some studies and research projects over the last 50 years.

Reduced participation in public life has also been studied recently in the US by Robert Putnam (2000), who argues that since 1950, the USA has experienced a strong decline in social capital; whereby, "all the forms of in-person social intercourse upon which Americans used to found and enrich the fabric of their social lives." The reduction in the degree of active civil engagement and political involvement worsens the quality of democracy. In a similar vein, Francis Fukuyama (1995) argues in a book dedicated to the analysis of trust and social capital that "though it may seem a stretch to compare Italy with the Confucian culture of Hong-Kong and Taiwan, the nature of social capital is similar in certain respects. In parts of Italy and in the Chinese cases, family bonds tend to be stronger than other kinds of social bonds not based on kinship, while the strength and number of intermediate associations between state and individual has been relatively low, reflecting a pervasive distrust of people outside the family. The consequences for industrial structure are similar: private sector firms tend to be relatively small and family-controlled, while large-scale enterprises need the support of the state to be viable."

The key finding is, therefore, that amoral familism tends to produce a special and stable social equilibrium, in which people exclusively trust and care about their immediate family: "expect everybody else to behave in that way, and therefore (rationally) do not trust non-family members and do not expect to be trusted outside the family" (Alesina-Giuliano, 2011) ${ }^{14}$. The "power of the family' on individuals tends to affect their degree of political participation; therefore, resulting in low civic engagement and low generalized trust, confidence in public life, and the quality of political institutions. Being convinced that politics is a private matter, people will not have the incentive to become engaged in political and public activities, except when this is completed out of self-interest alone. This kind of familism is predicted to hinder the development of high-quality political institutions, the pursuit of the common good, and participation in public affairs ${ }^{15}$.

In summary, there is clear evidence across the literature quoted above that:

a) In Southern European countries, the role of the family is very important; however, this is also true in many other developed and less developed countries;

b) Studies have demonstrated that countries where family matters tend to show less social capital, less participation, weaker political involvement, and a lower degree of trust;

c) Societies that rely heavily on families tend to have a lesser degree of trustworthiness and confidence in public institutions;

d) Family ties are often associated with negative economic performance, reduced rate of investment, and growth.

\footnotetext{
12 See Barzini (1964).

${ }^{13} \mathrm{~A}$ clear reference to this particular structure of the family was identified in the sixteenth century by Guicciardini (1983); at the start of the nineteenth century by Goethe (1983), Stendhal (1956) and Leopardi (1991); and more recently by Turiello (1882-1980), Salvemini (1928), Gramsci (1977), Putnam (1993) and Gambino (1998). The main, common point is that the strength of the family tends to hamper peoples' active participation in collective life.

${ }^{14}$ Alesina and Giuliano (2011) and Alesina and Giuliano (2010).

${ }^{15}$ As already mentioned, the importance of the family has also been largely acknowledged by Bisin and Verdier (2000, 2010).
} 
Therefore, the importance of the family and the key role of family ties have been already emphasized as a key factor to explain many economic, political and social dimensions, such as the quality of democracy, the political participation, the economic growth, and the quality and the intensity of social capital. Surprisingly, to our best knowledge, the family has not been used as an explaining factor for tax morale and the shadow economy and that is, therefore, the novelty of our study. We expect that countries where family ties are strong also tend to have a larger underground economy and a lower tax morale.

It is important to be clear about the possible implications of family ties. For instance, we are not saying that family ties are always bad... "Strong or weak family ties are neither "bad" nor "good" but they lead to different organizations of the family"16 and have different economic, moral, and social implications. There is some evidence, in fact, that happiness and life satisfaction is positively correlated with strong family ties. However, we believe that the investigation of these implications is crucial and worthwhile. In particular, Italy raises the issue of whether the strength of the family could be the main cause of weak political institutions and low social capital. However, a strong correlation does not necessarily imply causality. In other words, this brings up the complex problem of reverse causality: "do political institutions flourish only where the family is weak, or is it the other way around? Does the family become self-sufficient only where the political institutions are not strong enough?"17

When the role of the family is strong, civic duty tends to be low, along with social capital, tax morale, and tax compliance. When family ties are weak, on the other hand, trust in the public sector tends to result in higher tax morale and greater civic duty, while tax evasion tend to be lower. Therefore, in this paper we investigate whether family ties and the power of the family affect the size of the underground economy, trust and tax morale. To the best of our knowledge, this is the first study that attempts to address this issue.

\subsection{Role of the Parents and Family Ties}

There is, however, another interesting issue that we address in this paper. The power of the family in certain societies seems to strongly depend on the 'role of the mother' within the family. The different role of the father and the mother within the family should mostly explain the 'familial mentality,' which gives rise to loose collective responsibilities and civic involvements. Turiello (1887) and Bachofen (1949), Gambino (1998, 39-50) and Simone (2005) have argued that Italy, as a 'paese materno' (maternal country), tends to apply a familist mentality to social and public behaviors. It is important to emphasize that this mentality does not necessarily derive from the family itself, rather from the "female figure who is that of the woman as a "family's mother". It is not the family in a general sense that matters in this case ${ }^{18}$, but the role of the "woman-mother" that makes the 'familist mentality' as better described as 'maternal mentality'.

\footnotetext{
${ }^{16}$ Alesina and Giuliano (2011).

${ }^{17}$ Barzini $(1964,191)$. There is also another interesting issue, which was mentioned by Fukuyama (1999) and Putnam (1998), on possible links between family ties and maternal mentality, with the role of Catholic Church: "Italians in the South were much less likely to read newspapers, belong to unions, vote and otherwise take part in the political life of their communities than others. Moreover, people in the South expressed a much lower degree of social trust and confidence in the law-abiding behavior of their follow citizens. (...) Italian Catholicism correlates negatively with civicmindedness: when measured by indexes like attendance at mass, religious marriage, rejection of divorce, and so on, it grows stronger the farther south one moves, and civic-mindedness grows weaker" (Fukuyama 1995, 100).

18 See on this Gambino $(1998,40)$.
} 
Another interesting example of the key relevance of the family in Italian society comes from Barzini (1958): "Italy has often been defined as nothing more than a mosaic of millions of families, sticking together by blind instinct, like colonies of insects, an organic formation rather than a rational construction of written statutes and moral imperatives [...] there is nothing new, surprising or unique. In many countries and among many people, past and present, where legal authority is weak and the law is resented and resisted, the family mainly assures the safety and welfare of individuals. The Chinese, for instance, in their imperial days held the cult of the family more praiseworthy than the love of country and the love of good" but the same is also true in current times.

In human history, and in general, different types of families exist. Examples include (1) the nuclear patriarchal large family based on the concept of authority; (2) a family in which the role of the mother is prevalent with respect to that of the father; and (3) an extended family with weak constraints within their members.

The importance of mother mentality is at least true for Italy and most countries in Southern Europe (Spain, Portugal, Greece, etc.); however, clear similar characteristics also emerge for China and the Jewish tradition. ${ }^{19}$ However, it is important to stress that this distinction should not be based on the 'biological nature', rather on a 'cultural dimension' and should be identified as the product of a collective mental structure ${ }^{20}$. This 'mother mentality' tends to produce a specific collective attitude, which strengthens the blood ties among family members, implies a low level of civicness and a reduced degree of trust in other people and public institutions.

Of course, a very interesting issue may be to assess whether this phenomenon depends on the different role that a father usually has in educating children and transmitting moral values, as compared to that of the mother (i.e., we can call it as the 'absence of the father)' ${ }^{21}$.

The "mammismo," (mother culture), that largely pervades some societies, has been long acknowledged as a key characteristic of some specific society. This feature may be considered as the tendency to forgive, which comes out as a product of this widespread mother culture. The attitude to provide children with "an immediate and physical protection, with the removal of any possible fatigue or assumption of individual responsibility." ${ }^{22}$

The mother mentality is the opposite of the paternal approach: "the father takes care of external relations, is involved in war and defense activities." The father judges his children, and should provide them with the feeling for rules and order. The mother, instead, lives at home, is extremely protective, tends to justify (all) their children, and is fully dedicated to their development ${ }^{23}$. The mother has a key role in ensuring the species conservation and the perpetuation of the family. Therefore, the asymmetric role of the father and the mother within the family may largely explain the different effects of the family on individuals, which in turn influence economic behavior and

\footnotetext{
${ }^{19}$ Woody Allen's movies are in this regard an interesting reference: he frequently has a vision of his mother giving him many kinds of advice. On the importance of family in China, see Fukuyama (1995).

${ }^{20}$ See Gambino, 1998, 63.

${ }^{21}$ In the section of the paper where we run instrumental variables analysis, we show some empirical evidence on the opposite role of parents on family ties; the importance of the mother has a positive relationship with the strength of family ties.

22 Simone $(2005,84)$.

${ }^{23}$ There are many Italian films, movies and theatre pieces that are perfect examples of the feature of very comprehensive mothers who try to defend their heirs and to protect and justify their sons.
} 
civic and cultural values. This maternal mentality is per se far from any public morale and it inevitably damages the growth of any ethics, social accountability, and civicness ${ }^{24}$.

In this paper - see the online appendix - we also consider, as control variables, the importance of religion, trust and political participation as control variables. By using two different indexes of the importance of religion, we hypothesize that there might be, in general, a positive relationship between religion and the underground economy: when the importance of religion is high, the level of the shadow economy might tend to be greater. However, this is quite a controversial aspect whose analysis goes outside the scope of paper; in fact, one might also assume that stronger religiosity would involve more intense tax morale, an increased feeling for respecting norms and values, and, ultimately, a lower shadow economy. ${ }^{25}$ Finally, regarding the relationship between the shadow economy and the degree of trust in public institutions and other people, it seems reasonable to assume that when the degree of trust is higher, the level of the shadow economy becomes lower.

\subsection{Main contribution of the paper}

In conclusion, as a main contribution to the existing literature, the issue we address in this paper is very simple: amoral familism, particularly strong family ties, tends to influence the quality of institutions, since the final outcome is a particular type of civic involvement and political participation. All of this inevitably affects the degree of trust of various specific components of society; therefore, the way that people view public institutions tends to matter. Strong family ties induce less political participation, less trust in the public sector; hence this may affect tax morale and the underground economy in some way. In this paper, we provide therefore evidence that strong family ties are directly related to the underground economy, and are indirectly related to generalized trust and tax morale. By reducing the degree of social capital, family ties negatively affect tax morale and positively affect the dimension of the underground economy.

In this paper we therefore try to test the following hypothesis on family ties:

\section{- Family ties and underground economy hypothesis}

H1 the higher are family ties, the greater is the underground economy

\section{- Family ties and tax morale hypothesis}

$\mathrm{H} 2$ the higher are family ties, the lower is tax morale

While family ties have been largely and successfully used in some recent literature to explain the quality and intensity of political participation, the degree of trust and the level of social capital, to our best knowledge, this is the first attempt to estimate the role of family ties on the shadow economy and tax morale.

\footnotetext{
${ }^{24}$ As Salvemini summarized in 1928 "tax morale of Italians is essentially a family morale. Within the family range, each member helps each other with unconscious heroism, accepting as a duty event the worst sacrifice (...). But the social morale is loose. Government is considered as something unrelated and hostile to the people" (Salvemini, 1928). The familist mentality tends to produce a generalized tolerance for their members, which postpones any decisions needed, with adult age; "being a 'figlio di mamma' [mother son], the male-son deserves any justifications and pardon, "in any case.

${ }^{25}$ Some recent works show a clear negative correlation between religiosity and the underground economy: see, for example, Torgler and Schneider (2009), Heinemann-Schneider (2011), Torgler (2003).
} 


\section{Data description}

The empirical analysis presented in the paper is based on the construction of an original dataset which combines data on personal values and social features of different countries, with the percentage of underground economy.

Variables related to personal values are based on different waves of the WVS (World Value Survey) and EVS (European Value Survey). These research projects collect national surveys on values concerning a large number of issues: from perceptions of life to family values, from personal beliefs (on religion and civic participation) to political involvement, from national identity to public morale. The level of coverage changes every time, both with regard to the number of countries involved and the issues surveyed; however, a certain number of topics are investigated using the same questions in every wave. These surveys collect answers to a single questionnaire, which is usually made up of 140 questions for less than 400 variables, from a sample of approximately 1,500 people in each country.

Data on the underground economy are taken from Medina and Schneider (2017) who define the underground economy in the usual way: "the shadow economy reflects mostly the legal economic and productive activities, that, if recorded, would contribute to national GDP". In this way, the authors avoid addressing other components of the activities of the shadow economy, such as crime or other types of illegal actions. On the definitions and measurement of underground economy see also Schneider (2005), Schneider and Enste (2000, 2002), and Schneider et al. (2010).

Table 1 presents the list of all variables and data sources that we use for the empirical analysis. We use three different waves, both for World Value Survey and for the European Value Survey. For the first Survey, we use the waves of 1989-1993, 1999-2004, and 2005-2008, while for the second Survey, we use those carried out in 1990, 1999, and 2008. In Table 2 the usual descriptive statistics are summarized together with the number of observations for each variable.

In total in our dataset we include information for 92 countries ${ }^{26}$ over a period of 20 years from 1992 up to 2011. However, the presence of missing information for family ties values and/or the level of underground economy shrinks the regression sample of roughly 800 observations. The distribution of the panel structure is shown in Figure 1, where, as a time variable, we consider the year when the interview took place in each country. Information for intra wave period have been replicated in order to complete the panel structure.

\footnotetext{
${ }^{26}$ Albania, Algeria, Andorra, Argentina, Armenia, Australia, Austria, Azerbaijan, Bangladesh, Belarus, Belgium, Bosnia Herzeg, Brazil, Bulgaria, Burkina Faso, Canada, Chile, China, Colombia, Croatia , Czech Republic, Denmark, Egypt, Estonia, Ethiopia, Finland, France, Georgia, Germany, Ghana, Great Britain, Greece, Guatemala, Hong Kong, Hungary, Iceland, India, Indonesia, Iran, Iraq, Ireland, Israel, Italy, Japan, Jordan, Korea (South), Kyrgyzstan, Latvia, Lithuania, Luxembourg, Macedonia, Malaysia, Mali, Malta, Mexico, Moldova, Morocco, Netherlands, New Zealand, Nigeria, Norway, Pakistan, Peru, Philippines, Poland, Portugal, Puerto Rico, Romania, Russian Federation, Rwanda, Saudi Arabia, Singapore, Slovak Republic, Slovenia, South Africa, Spain, Sweden, Switzerland, Taiwan, Tanzania, Thailand, Trinidad and Tobago, Turkey, Uganda, Ukraine, United States, Uruguay, Venezuela, Viet Nam, Zambia, Zimbabwe.
} 
Table 1. Description, source, and availability of variables

\begin{tabular}{|c|c|c|c|}
\hline Variable & Description & Source & Availability \\
\hline \multicolumn{4}{|c|}{ Dependent variables (Shadow economy, tax morale) } \\
\hline $\begin{array}{l}\text { Underground } \\
\text { economy }\end{array}$ & Shadow economy (\% of GDP) & Schneider (2017) & $1992-2011$ \\
\hline Tax morale & $\begin{array}{l}\text { Principal component among "claiming", "cheating," "bribe," } \\
\text { and "transport" }\end{array}$ & \multirow{5}{*}{$\begin{array}{l}\text { World Value Survey; } \\
\text { European Value Survey }\end{array}$} & \multirow{5}{*}{$1992-2011$} \\
\hline Claiming & "do you justify: claiming state benefits" (1=never, 10=always) & & \\
\hline Cheating & "do you justify: cheating on tax" (1=never, 10=always) & & \\
\hline Bribe & "do you justify: accepting a bribe" (1=never, 10=always) & & \\
\hline Transport & $\begin{array}{l}\text { "do you justify: avoiding fare on public transport" (1=never, } \\
10=a l w a y s)\end{array}$ & & \\
\hline \multicolumn{4}{|l|}{ Family ties } \\
\hline $\begin{array}{l}\text { Family ties } \\
\text { principal component }\end{array}$ & $\begin{array}{l}\text { Principal component among "family," "loveparents", and } \\
\text { "helpchild" }\end{array}$ & \multirow{4}{*}{$\begin{array}{l}\text { World Value Survey; European } \\
\text { Value Survey }\end{array}$} & \multirow{4}{*}{$1992-2011$} \\
\hline $\begin{array}{l}\text { Importance of } \\
\text { family }\end{array}$ & $\begin{array}{l}\text { "how important is family in your life" (1=very important, 4=not } \\
\text { at all important) }\end{array}$ & & \\
\hline Love parents & $\begin{array}{l}\text { "love and respect parents" } \\
\text { (1=agree, } 2=\text { disagree })\end{array}$ & & \\
\hline Help child & $\begin{array}{l}\text { "parents should sacrifice own wellbeing for their children" } \\
\text { (1=agree, } 2=\text { disagree) }\end{array}$ & & \\
\hline Role of the mother & $\begin{array}{l}\text { "relationship between you and your mother" (1=very close, } \\
\text { 3=not very close) }\end{array}$ & \multirow{2}{*}{ European Value Survey } & \multirow{2}{*}{1981} \\
\hline Role of the father & $\begin{array}{l}\text { "relationship between you and your father" (1=very close, } \\
\text { 3=not very close) }\end{array}$ & & \\
\hline \multicolumn{4}{|l|}{ Control variables } \\
\hline Tax burden & Cash receipts from taxes (\% of GDP) & World Bank, revenue data & \multirow{8}{*}{$1992-2011$} \\
\hline Importance of religion & $\begin{array}{l}\text { "how important is religion in your life" (1=very important, } \\
\text { 4=not at all important) }\end{array}$ & \multirow{7}{*}{$\begin{array}{l}\text { World Value Survey; European } \\
\text { Value Survey }\end{array}$} & \\
\hline Religious person & $\begin{array}{l}\text { "are you a religious person" (1=religious person, } 3=\text { convinced } \\
\text { atheist) }\end{array}$ & & \\
\hline Trust church & $\begin{array}{l}\text { "how much confidence do you have in church" (1=a great deal, } \\
\text { 4=none at all) }\end{array}$ & & \\
\hline Trust people & "people can be trusted" (1=agree, $2=$ disagree) & & \\
\hline Trust parliament & $\begin{array}{l}\text { "how much confidence you have in the parliament" (1=a great } \\
\text { deal, } 4=\text { none at all) }\end{array}$ & & \\
\hline $\begin{array}{l}\text { Importance of } \\
\text { politics }\end{array}$ & $\begin{array}{l}\text { "how important is politics in your life" (1=very important, } \\
\text { 4=not at all important) }\end{array}$ & & \\
\hline Political orientation & political view: left-right ( $1=$ left, $10=$ right $)$ & & \\
\hline
\end{tabular}


Table 2. Descriptive statistics (regression sample), averages by country over the entire time period of analysis

\begin{tabular}{|c|c|c|c|c|c|}
\hline Variable & Mean & Std. Dev. & Min & Max & Obs(*) \\
\hline \multicolumn{6}{|c|}{ Dependent variables (Shadow economy, tax morale) } \\
\hline $\begin{array}{l}\text { Underground } \\
\text { economy }\end{array}$ & 23.79 & 11.77 & 6.16 & 69.08 & 794 \\
\hline Tax morale & 1.99 & 0.51 & 1.20 & 4.14 & 794 \\
\hline Claiming & 1.98 & 0.43 & 1.00 & 4.08 & 794 \\
\hline Cheating & 1.60 & 0.34 & 1.02 & 3.36 & 794 \\
\hline Bribe & 2.05 & 0.45 & 1.09 & 4.46 & 794 \\
\hline Transport & 23.79 & 11.77 & 6.16 & 69.08 & 794 \\
\hline \multicolumn{6}{|l|}{ Family ties } \\
\hline $\begin{array}{l}\text { Family ties } \\
\text { principal component }\end{array}$ & 0.04 & 0.97 & -1.95 & 2.54 & 745 \\
\hline $\begin{array}{l}\text { Importance of } \\
\text { family }\end{array}$ & 1.15 & 0.08 & 1.01 & 1.42 & 794 \\
\hline Love parents & 1.25 & 0.16 & 1.03 & 1.73 & 745 \\
\hline Help child & 1.38 & 0.18 & 1.05 & 1.93 & 745 \\
\hline Role of the mother & 1.59 & 0.12 & 1.43 & 1.78 & 234 \\
\hline Role of the father & 1.81 & 0.15 & 1.64 & 2.17 & 234 \\
\hline \multicolumn{6}{|l|}{ Control variables } \\
\hline Tax burden & 18.64 & 5.97 & 4.99 & 35.09 & 794 \\
\hline Importance of religion & 2.23 & 0.61 & 1.02 & 3.19 & 794 \\
\hline Religious person & 1.37 & 0.23 & 1.03 & 2.01 & 794 \\
\hline Trust church & 2.28 & 0.49 & 1.12 & 3.39 & 794 \\
\hline Trust people & 1.69 & 0.17 & 1.24 & 1.96 & 794 \\
\hline Trust parliament & 2.71 & 0.32 & 1.65 & 3.38 & 794 \\
\hline $\begin{array}{l}\text { Importance of } \\
\text { politics }\end{array}$ & 2.74 & 0.26 & 1.96 & 3.24 & 794 \\
\hline Political orientation & 5.49 & 0.56 & 3.59 & 7.56 & 794 \\
\hline
\end{tabular}

(*) The number of observations is restricted to municipalities with no missing values in all variables.

Figure 1. Panel structure

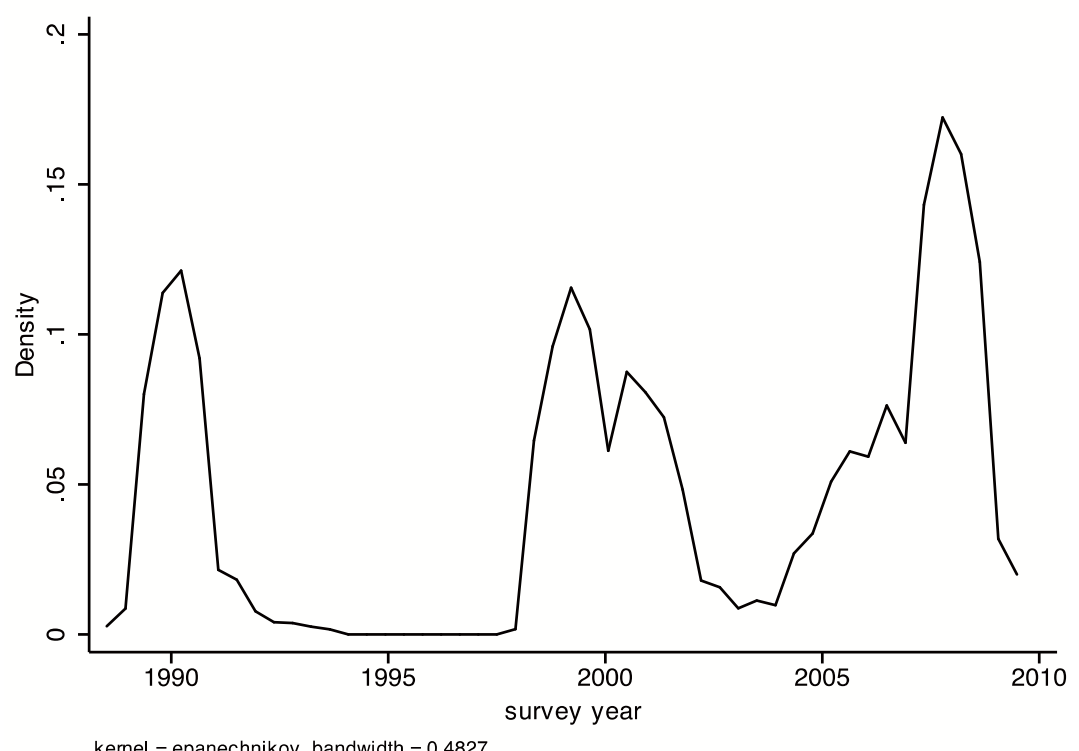


The strength of the family ties can be measured considering three WWS variables. First of all, the variable that denotes directly the importance of the family (importance of family), which collects opinions about the importance of the family from 1 , indicating high importance to 4 indicating less importance. The two other variables, instead, capture the strength of the family ties indirectly and from different angles: the relevance of love and respect for one's own parents (love parents), and the duties and responsibilities of parents towards children (help child). In particular, the variable "love parents" measures how the respondent agrees with one of two statements: a) "Regardless of what the qualities and faults of one's parents are, one must always love and respect them;" or b) "One does not have the duty to respect and love parents who have not earned it" The variable "help child" captures to what extent the respondent agrees with one of the two statements: a) "It is the parents' duty to do their best for their children even at the expense of their own wellbeing;" or b) "Parents have a life of their own and should not be asked to sacrifice their own wellbeing for the sake of their children." The first option for both questions takes the value of 1 , while the second alternative takes the value of 2 .

Figure 2 shows the fitted value lines that exist between the variables used to measure the strength of family ties and underground economy (as an average by country from 1992 to 2011). With all types of measures, the negative slope confirms that when the intensity of family ties decreases (a higher numerical value), the size of the shadow economy also decreases.

Figure 2. Relationship between family ties' variables and underground economy (original measure of scale, 1 = high family ties), average 1992-2011.
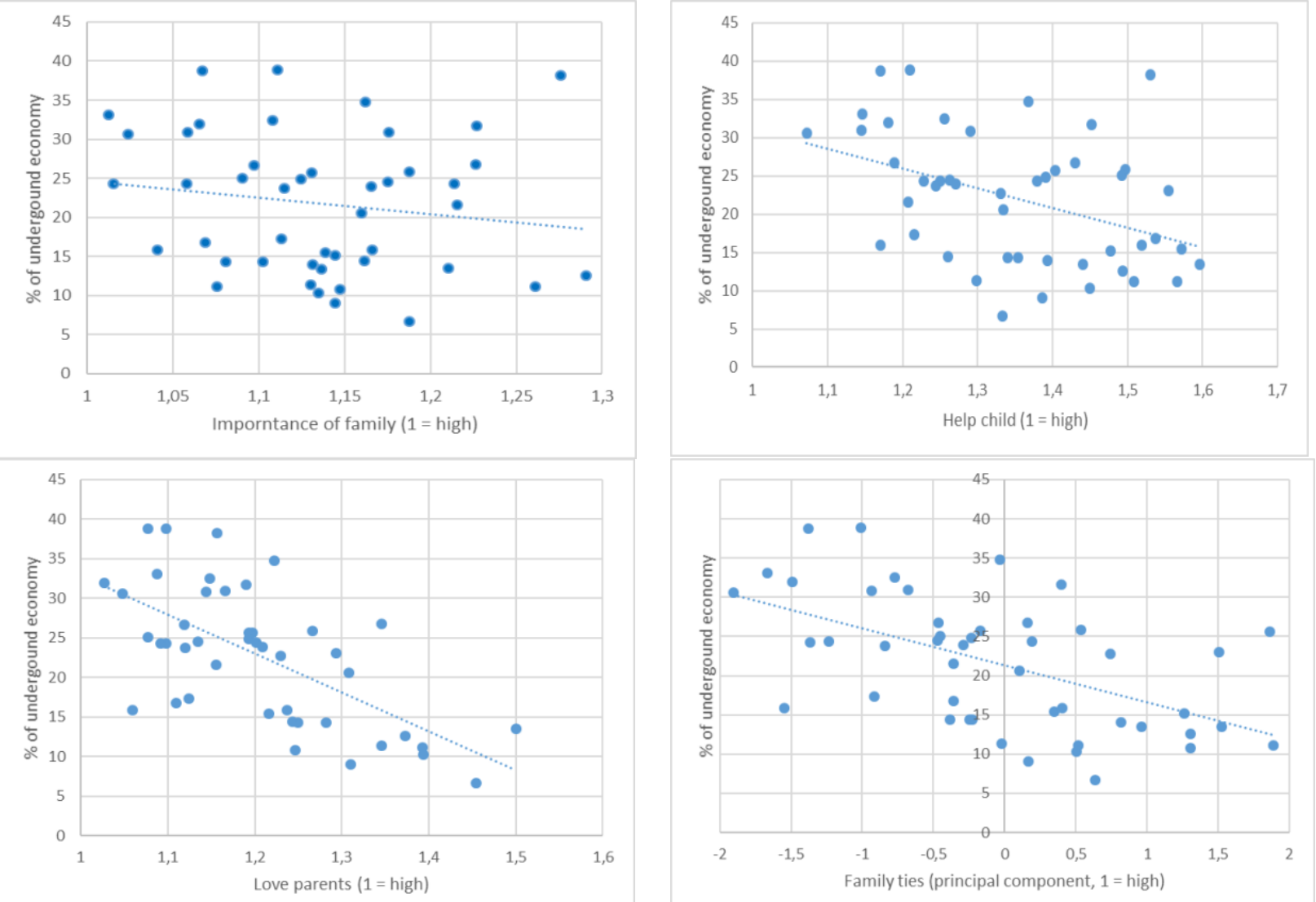

Notes. Countries that show a percentagage of underground economy on average above $40 \%$ have been excluded from the picctur since treated as outliers (Georgia, Guatemala, Peru, Belarus, Ukraine, Azerbaijan and Moldova).

In order to study the potential causal effect exerted by the strength of family ties on the level of shadow economy and tax morale we need to investigate the intrinsic social features that shape 
the structure of family ties. For this scope, as a determinant of the importance of the family in people life, we use two variables from the 1981 EVS measuring the role of the parents in the family. In particular, the variables "role of the mother" and "role of the father" measure how the respondent answered, respectively, to the following questions: "How was the relationship between you and your mother?" "How was the relationship between you and your father?" In both questions we observe the following scale: $1=$ very close, $3=$ not very close. Both questions were not repeated in other waves of the EVS or WWS and are available only for 14 countries in our sample ${ }^{27}$. For a detailed discussion on the relationship between the role of the parents and the strength of family ties see Section 4.1.

Figure 3 shows, for the 14 countries with available data, the strong correlation between the importance of the family and the importance of the role of the parents. As expected, countries where family ties are more intense tend to show a larger importance in the role of the mother and the father.

Figure 3. Relationship among family ties, role of the mother, the role of the father (1992-2011)
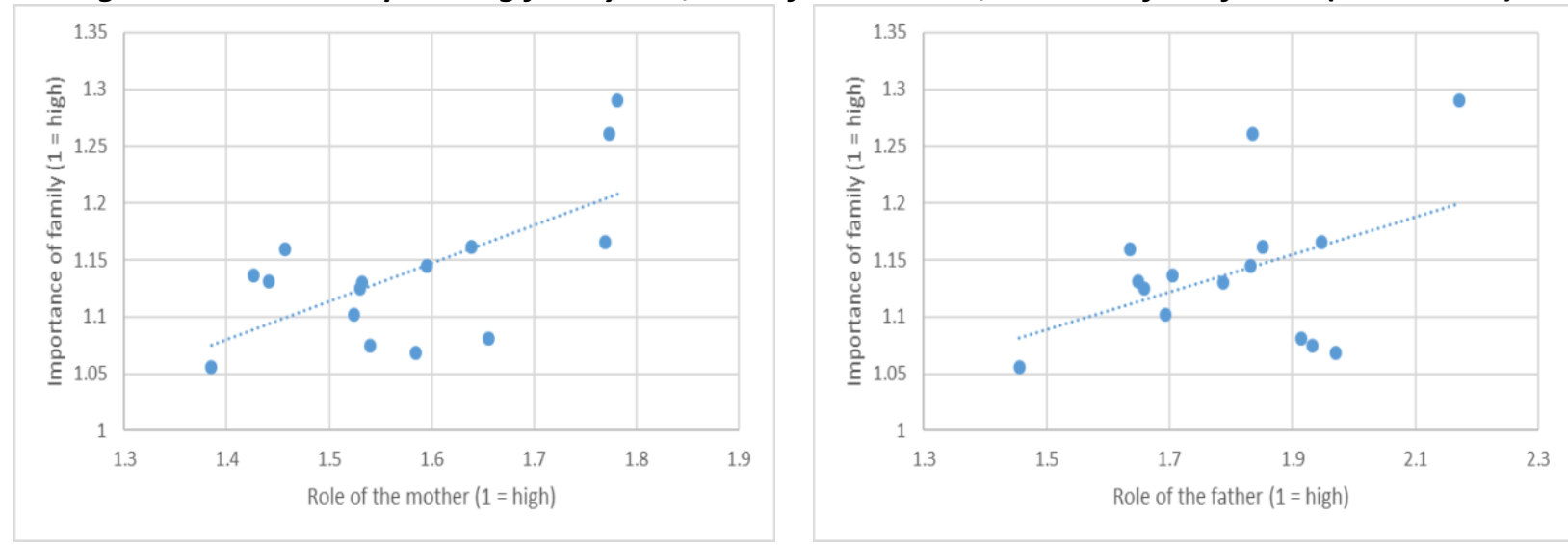

Tax morale measures the willingness of people to behave honestly in matters of the public sector domain. Both the WWS and EVS report a wide range of tax morale issues. In these surveys, tax morale has been measured with different dimensions, such as: a) claiming state benefits which you are not entitled to; b) accepting bribes in the course of one's duties; c) avoiding payment of tickets on public transport; d) cheating on taxes if you have the chance (see Table 1). People have been asked to express their opinion according to the following scale: "Please tell me whether you think the following statements can always be justified, never justified, or something in between: (...)". The answers are classified from 1 to 10, where 1 is for never justifiable and 10 is for always justifiable.

Figure 4 displays the fitted value lines that exist between the variables used to measure the strength of family ties and the level of tax moral considering the principal component of the variables describe above (as an average by country from 1992 to 2011) and considering a larger number associated with higher tax morale. With all types of measures, the positive slope confirms that when the intensity of family ties decreases (a higher numerical value), the level of tax morale seems to be higher.

${ }^{27}$ Malta, Belgium, Italy, Ireland, Great Britain, Iceland, United States, Denmark, France, Canada, Netherlands, Germany. 
Figure 4. Relationship between family ties' variables and tax morale (original measure of scale, $1=$ high family ties), average 1992-2011.
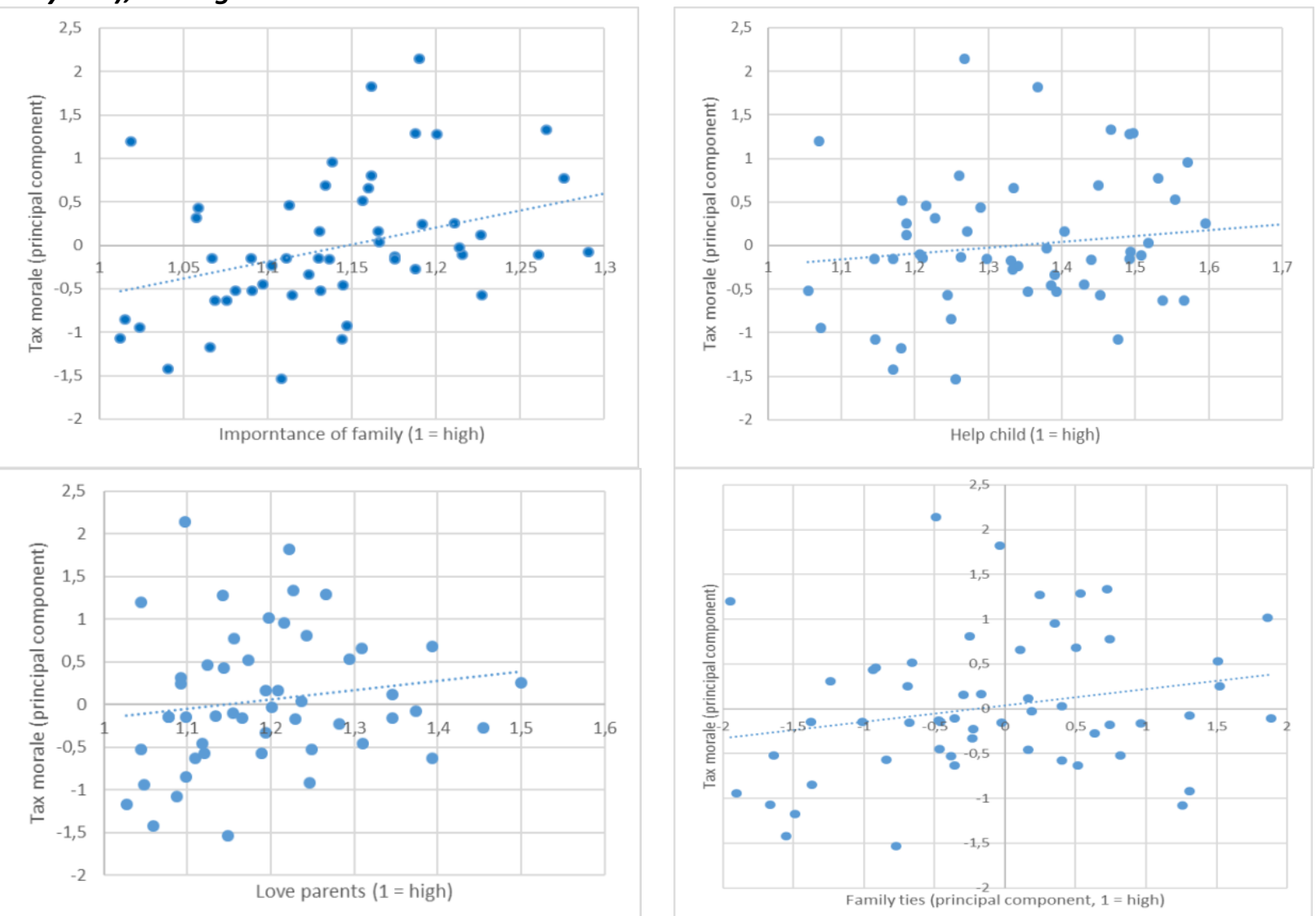

Notes. Countries that show a percentagage of underground economy on average above $40 \%$ have been excluded from the picctur since treated as outliers (Georgia, Guatemala, Peru, Belarus, Ukraine, Azerbaijan and Moldova).

In order to ensure, as much as possible, that our empirical models are correctly specified we have also collected information related to a wide set of control variables that capture different features of the society such as: the level of trust, the importance of politics and the importance of religion. Although the relationship among these social features and underground economy are out of the scope of this paper it is important to take them into account in order to minimize the omitted variable bias in the study of relationship between family ties and the level of underground economy. In the rest of the paragraph we provide a brief description of the set of control variables included in the analysis.

We measure the degree of trust in three dimensions: trust in other people, trust in public institutions and trust in religion. As far as the first dimension of trust is concerned, we survey the degree of trust in other people by using a variable based on the following question: "Generally speaking, can most people be trusted or do you (the respondent) need to be very careful in dealing with people?" Two alternative answers were possible: a) "most people can be trusted" or b) "you need to be very careful". We survey the last two dimensions of trust by using a set of two different variables, which are based on the answers to the questions that investigate the level of trust in the following institutions: the parliament and the church. Respondents are requested to express their degree of trust in these institutions on a scale that ranges from 1 to 4 , where option 1 represents "high trust" and option 4 represents "no trust at all." 
We check the role of religion in people's life by using a set of two different variables. The first variable is linked to the question that investigates whether the respondent considers himself to be a religious person: "Independently of whether you attend Church services, do you consider yourself to be a religious person?". Answers vary from 1 to 3, where option 1 represents "a religious person", option 2 represents "a non-religious person", and option 3 represents "an atheist." The second variable checks the importance of religion in one's own life. The variable refers to the following question: "... indicate how important religion is in your life." The answers range from 1 to 4, where option 1 represents "very important" and option 4 represents "not important at all".

In conclusion, to measure the importance of politics in one's own life, we use a variable linked to a question that specifically investigates this subject. Answers to the question range from 1 to 4 , where 1 represents very important and 4 represents not important at all. We also use a variable that measures people political orientation on a scale from 1 (left) to 10 (right) (see table 1 ).

\section{Empirical strategy}

Family values and family ties are variables that tend to be strongly persistent across time within the same countries. In fact, these values tend to change very slowly across time, but exhibit huge differences between countries, as known in the history of the humankind.

We have clear examples that the family is one of the more lasting institutions (including in old China, Italy, and North Africa), and that its role tends to be persistent and to change very slowly across time. According to our estimates, more than $55 \%$ of the variance of family ties in our sample of over 110,000 individual observations is explained by a country-fixed effect. The same result has been reported by Bertrand and Schoar (2006) in a paper on the role of the family on the size of firms. In parallel, we interpret "these findings as supportive of the view that family norms have a larger country level component" rather than individual variations within each country.

Therefore, we believe that the best empirical strategy to capture the relationship among family ties, tax morale and underground economy is to estimate a linear panel data model with the individual data (available for family ties and tax morale) collapsed at the country level to control for a real country-fixed effect ${ }^{28}$.

\subsection{The empirical model}

To measure the impact of family ties on the level of the shadow economy and tax morale, when controlling for the other factors that may affect the individual behavior towards tax evasion and tax morale, we estimate the following linear panel data model reported in equation (1):

$Y_{i t}=\beta_{0}+\beta_{1 \text { familytiesit }}+\beta_{2}$ fiscalit $+\beta_{3 \text { politicsit }}+\beta_{4 \text { trustit }}+\beta_{\text {sreligion } i t}+\alpha_{i}+\eta_{t}+\varepsilon$ it

where $i$ is the country index and $t$ is the year index.

28 In a recent paper, in contrast to the mainstream literature, Ljunge (2013) finds a positive relationship between the strength of family ties and the degree of tax morale. We believe that these surprising results are due to the fact that the author is using individual data and country-dummies as an additional regressor; therefore, "its results are based on within-country variation," ignoring the main component of between-country variation. 
The dependent variable $Y_{i t}$ is, in turn, the percentage of underground economy and the level of tax morale measured by using the principal component of the four previously described variables: Cheating on taxes, Claiming benefits, Bribe, and Transport. ${ }^{29}$

The strength of family ties is captured by three variables "importance of family", "love parents", "help child". However, in the baseline specification we used directly the variable importance of family; as a second option we use the principal component of the variables importance of family, love parents and help child. Instead, other results (included those of the principal component analysis) are reported in the online appendix.

Therefore, the entire empirical analysis will be focused on the computation of reliable and robust point estimates for the $\beta_{1}$ coefficient of the baseline model reported in equation (1).

In the most complete specification of the model we are considering four groups of control variables (see Table 1 and 2 for a complete description of the variables).

1. The impact of tax burden is measured using the variable Fiscal, which corresponds to the ratio between revenue from taxes over GDP published by the World Bank.

2. The role of politics is measured in terms of the Importance of politics in people's life and a variable related to the Political orientation between left and right.

3. The level of trust is measured using three variables: Trust government and Trust church related to the confidence in public institutions, and Trust people related to the confidence in other citizens.

4. The role of religion is measured using two variables: Importance of Religion and Religious person.

Since we are using a fixed-effect panel data model estimator, $\alpha_{i}$ is the country fixed effect and $\eta_{t}$ is the year effect, which is captured using year dummies.

The stochastic components $\varepsilon i t$ is assumed, as usual, to be i.i.d $(0, \sigma)$.

The empirical model in equation (1) has been specified as a Fixed Effect (FE) linear panel data model, and the coefficients point estimates have been obtained using the Within-the-Group (WG) estimator. As far as the magnitude of the coefficients is concerned, all variables have been standardized to make them comparable.

In order to make the results more readable, all variables have been reversed (multiplied by -1 ). So that, for all variables, the numerical values are in line with the meaning of the variable; hence, their values increase with the intensity of the variable.

After our FE panel estimates, we use the variables "role of the mother" and "role of the father" as instrumental variables for family ties. In this way, we study the possible causal effects exerted by family ties on underground economy and on the level of tax morale. It is important to underline that in the instrumental variable (IV) analysis we cannot specify any more the model as a FE linear panel data since both instruments are time invariant. In fact, after 1981 EVS wave, the questions on the role of parents in the family were not replicated in more recent versions of the surveys. Our

\footnotetext{
${ }^{29}$ Results of the principal component analysis are shown in the online appendix.
} 
two stages empirical strategy is described in the equations (2) and (3), that correspond, respectively, to the first and the second stage of the IV analysis.

familytiesit $=\gamma_{0}+\gamma_{1}$ role_mother $i+\gamma_{2}$ role_father $i+\gamma_{3}$ fiscalit $_{2}+\gamma_{4}$ politicsit $+\gamma_{5 \text { trustit }}+\gamma_{6}$ religionit $+\phi_{i t}$

$Y_{i t}=\eta_{0}+\eta_{1}$ familyties_fitted $_{i t}+\eta_{22}$ fiscalit $+\eta_{3}$ politicsit $+\eta_{4}$ trustit $+\eta_{5}$ religionit $+\theta_{i t}$

Where the variable familyties_fitted in equation (3) corresponds to the fitted values of the first stage regression reported in equation (2).

It is important to stress that the two stages are estimated simultaneously using a "two stage least square estimator" (2SLS) in order to perform correct inference analysis on the $\eta_{s}$ coefficients. With the IV strategy, $\eta_{1}$ point estimates will provide a measure of the causal effect that the strength of the family ties will produce on underground economy and tax morale, thus corroborating the results obtained with the $B_{1}$ point estimates of the baseline model reported in equation (1).

\subsection{Results}

In line with the discussion reported in Sections 4 and 5, we expect a positive relationship between the level of the shadow economy and the strength of family ties; namely, the stronger the family ties, the higher the level of the underground economy. Instead, we expect a negative relationship between the level of the tax morale and the strength of family ties; namely, the stronger the family ties, the higher the numeric value of cheating on taxes (that is to say, a lower index of tax morale).

Table 3, from column (1) to (3) presents the point estimates of the coefficient $\beta_{1}$ of the model specified in equation (1) considering the percentage of underground economy as a dependent variable. The level of family ties is measured by using the variable "importance of the family" and principal component of the variables help child, love parents, and the importance of the family. In particular, with all of the specifications, we observe that, the level of the shadow economy is high when family ties are strong. The magnitude and the statistical significance of the coefficients remain always high, although it becomes weaker as we increase the number of control variables. ${ }^{30}$

\footnotetext{
${ }^{30}$ In other specifications, where we use the variables love parents and help child individually, as a measure of family ties, their impact on the degree of the shadow economy remains, in most of the cases, positive and statistically very significant. Tables with these additional results are available in the online appendix.
} 
Table 3. Point estimates of the impact of family ties on the shadow economy

\begin{tabular}{|c|c|c|c|c|c|}
\hline & $\begin{array}{l}\text { (1) } \\
\mathrm{FE}\end{array}$ & $\begin{array}{l}\text { (2) } \\
\mathrm{FE}\end{array}$ & $\begin{array}{l}\text { (3) } \\
\text { OLS }\end{array}$ & $\begin{array}{c}(4) \\
\text { OLS } \\
\text { (restricted } \\
\text { sample) }\end{array}$ & $\begin{array}{c}(5) \\
2 \text { SLS } \\
\text { (restricted } \\
\text { sample) }\end{array}$ \\
\hline Importance of the family $\left({ }^{* * *} p<0.01, * * p<0.05, * p<0.1\right)$ & $0.0397^{*}$ & $0.0669 * * *$ & 0.0048 & 0.0496 & $0.9759 * * *$ \\
\hline Robust standard errors in brackets & [0.024] & [0.023] & [0.032] & [0.035] & [0.179] \\
\hline Observations & 907 & 907 & 907 & 280 & 280 \\
\hline R-squared & 0.630 & 0.574 & 0.013 & 0.639 & \\
\hline Underidentification test (Kleibergen-Paap rk LM statistic): & & & & & 25.24 \\
\hline Chi-sq(2) P-val & & & & & 0.0000 \\
\hline Weak identification test (Kleibergen-Paap rk Wald F statistic): & & & & & 21.217 \\
\hline Overidentification test of all instruments (Hansen J statistic): & & & & & 0.318 \\
\hline Chi-sq(1) P-val & & & & & 0.5726 \\
\hline Family ties, principal comp. $\left({ }^{* * *} p<0.01, * * p<0.05, * p<0.1\right)$ & $0.0512 *$ & $0.0593 * *$ & $0.4273^{* * *}$ & 0.0215 & $1.1147^{* * *}$ \\
\hline Robust standard errors in brackets & [0.026] & [0.024] & [0.031] & [0.044] & [0.244] \\
\hline Observations & 858 & 858 & 858 & 280 & 280 \\
\hline R-squared & 0.659 & 0.601 & 0.180 & 0.637 & \\
\hline Underidentification test (Kleibergen-Paap rk LM statistic): & & & & & 18.817 \\
\hline Chi-sq(2) P-val & & & & & 0.0001 \\
\hline Weak identification test (Kleibergen-Paap rk Wald F statistic): & & & & & 10.152 \\
\hline Overidentification test of all instruments (Hansen J statistic): & & & & & 5.597 \\
\hline Chi-sq(1) P-val & & & & & 0.018 \\
\hline Constant & Yes & Yes & Yes & Yes & Yes \\
\hline Control variables & Yes & No & No & Yes & Yes \\
\hline Fixed effect & Yes & Yes & No & No & No \\
\hline Year dummies & Yes & Yes & Yes & Yes & Yes \\
\hline \multicolumn{6}{|c|}{$\begin{array}{l}\text { Notes. All variables are standardized and their values increase with the intensity of the variable. Coefficient point estimates must be interpreted in } \\
\text { terms of standard deviations of the dependent variables generated by one standard deviation of the regressors. Years dummies included in the } \\
\text { estimates are from } 1992 \text { to } 2011 \text {. The set of controls includes variables related to the level of the general tax burden, trust, importance of polities, } \\
\text { role of religion and political orientation. Coefficients of the FE Panel data models are estimated trough the Within the Group estimator with } \\
\text { standard errors clustered at country level. The restricted sample includes the } 14 \text { countries for which the instrumental variables "Role of the } \\
\text { mother" and "Role of the father" are available (Belgium, Canada, Denmark, France, Germany, Great Britain, Iceland, Ireland, Italy, Malta, } \\
\text { Netherlands, Norway, Spain, Sweden, and United States). Hansen J statistic has been performed excluding United States and Malta. }\end{array}$} \\
\hline
\end{tabular}

Table 4, from column (1) to (3) presents the point estimates of the coefficient $\beta_{1}$ of the model in equation (1), now the dependent variable is the principal component of the variable used to measure the level of tax morale. The level of family ties is measured by using the variable "importance of the family" and principal component of the variables help child, love parents, and the importance of the family (results with other alternative measures of family ties are presented in the online appendix). In particular, in column (3) where we perform a simple OLS without country fixed effect, we observe a strong positive relationship between family ties and tax morale. However, when we introduce the country-fixed effect, the sign of the coefficient become negative, in line with the mainstream literature. This result indicates that "strong family ties imply weak tax morale". 


\begin{tabular}{|c|c|c|c|c|c|}
\hline & $\begin{array}{l}\text { (1) } \\
\mathrm{FE}\end{array}$ & $\begin{array}{l}\text { (2) } \\
\mathrm{FE}\end{array}$ & $\begin{array}{l}\text { (3) } \\
\text { OLS }\end{array}$ & $\begin{array}{c}\text { (4) } \\
\text { OLS } \\
\text { (restricted } \\
\text { sample) }\end{array}$ & $\begin{array}{c}(5) \\
2 S L S \\
\text { (restricted } \\
\text { sample) }\end{array}$ \\
\hline Importance of the family $\left({ }^{* * *} p<0.01, * * p<0.05, * p<0.1\right)$ & $-0.5638 * *$ & $-0.4634 * *$ & $0.2891 * * *$ & $-0.2387^{* * *}$ & $-0.4953 * * *$ \\
\hline Robust standard errors in brackets & [0.254] & [0.222] & [0.035] & [0.048] & [0.085] \\
\hline Observations & 879 & 879 & 879 & 280 & 280 \\
\hline R-squared & 0.280 & 0.203 & 0.129 & 0.673 & 0.642 \\
\hline Underidentification test (Kleibergen-Paap rk LM statistic): & & & & & 83,495 \\
\hline Chi-sq(2) P-val & & & & & 0,0000 \\
\hline Weak identification test (Kleibergen-Paap rk Wald F statistic): & & & & & 68,61 \\
\hline Hansen J statistic (overidentification test of all instruments): & & & & & 2,153 \\
\hline Chi-sq(1) P-val & & & & & 0,1422 \\
\hline Family ties, principal comp. $\left({ }^{* * *} p<0.01, * * p<0.05, * p<0.1\right)$ & 0.1061 & 0.1095 & $0.1708^{* * *}$ & $-0.1182 * *$ & $-1.3124^{* * *}$ \\
\hline Robust standard errors in brackets & [0.163] & [0.193] & [0.041] & [0.056] & [0.363] \\
\hline Observations & 830 & 830 & 830 & 280 & 280 \\
\hline R-squared & 0.229 & 0.160 & 0.090 & 0.652 & 0.092 \\
\hline Underidentification test (Kleibergen-Paap rk LM statistic): & & & & & 15,591 \\
\hline Chi-sq(2) P-val & & & & & 0,0004 \\
\hline Weak identification test (Kleibergen-Paap rk Wald F statistic): & & & & & 7,925 \\
\hline Hansen J statistic (overidentification test of all instruments): & & & & & 0,098 \\
\hline Chi-sq(1) P-val & & & & & 0,7547 \\
\hline Constant & Yes & Yes & Yes & Yes & Yes \\
\hline Control variables & Yes & No & No & Yes & Yes \\
\hline Fixed effect & Yes & Yes & No & No & No \\
\hline Year dummies & Yes & Yes & Yes & Yes & Yes \\
\hline \multicolumn{6}{|c|}{$\begin{array}{l}\text { Notes. All variables are standardized and their values increase with the intensity of the variable. Coefficient point estimates must be interpreted } \\
\text { in terms of standard deviations of the dependent variables generated by one standard deviation of the regressors. Years dummies included in } \\
\text { the estimates are from } 1992 \text { to } 2011 \text {. The set of controls includes variables related to the level of the general tax burden, trust, importance of } \\
\text { polities, role of religion and political orientation. Coefficients of the FE Panel data models are estimated trough the Within the Group estimator } \\
\text { with standard errors clustered at country level. The restricted sample includes the } 14 \text { countries for which the instrumental variables "Role of the } \\
\text { mother" and "Role of the father" are available (Belgium, Canada, Denmark, France, Germany, Great Britain, Iceland, Ireland, Italy, Malta, } \\
\text { Netherlands, Norway, Spain, Sweden and United States). }\end{array}$} \\
\hline
\end{tabular}

Our results provide empirical evidence in support of the two crucial points that constitute the focus of the paper: for the first time we provide clear evidence of a positive correlation between the strength of the family ties and underground economy; as already highlighted by Bertand and Schoar (2006) and Alesina and Giuliano (2010, 2011), there is evidence of a strong negative correlation between the level of tax morale and the strength of family ties.

Moreover, comparing the results in column (1) of Tables 3 and 4 we can notice that the magnitude of the impact of the "importance of family" on "tax morale" is much higher (more than ten times larger) than what observed in case of underground economy. However, we believe that these coefficients might be downward biased because of the problem of reverse causality between family ties, underground economy and tax morale. To address this last issue - as discussed in more detail in the next paragraph - we perform an instrumental variables (IV) analysis. 


\section{3. instrumental variables analysis}

To interpret the relationship observed among family ties, underground economy and tax morale in terms of a causal relationship - i.e. provide econometric evidence in support of the role played by the strength of family ties as a determinant of tax evasion - we perform an IV exercise using the variables 'role of the mother and role of the father', registered in the 1981 European Value Survey, as instruments for the variables love parents, help child, and importance of family used to capture the strength of family ties.

Evidence in support of the validity of our instrumental variables exercise is shown in Table 5 were we report the OLS point estimates of the first stage model specified in line with equation (2). In particular, both instrumental variables exhibit a robust impact on our measures of family ties. The importance of the mother is always positively correlated with family ties, instead the role of the father is less stable but nevertheless correlated: it shows a positive correlation with family ties when the role of mother is not included in the specification of the model, instead when both variables are included it turns negatively correlated with family ties (compare column 1 and 3 of Table 5). It is not clear how this familial pattern may be explained. Is the intensity of family ties a product of an excessive role of the mother, or is it due to the absence of the father? We may suppose, in certain circumstances, at least in current modern society, a joint and opposite effect of these characteristics, even if the role of the mother tends to supersede that of the father. However, from the econometric point of view, both variables can be used as instruments of our IV analysis as formally shown with the support of the tests reported in column (5) of Tables 3 and 4, where the final results of the IV exercise are reported. Instead, for a more general discussion on the validity of our IV strategy see Section 4.1.

Columns (4) and (5) of Table 3 show, respectively, the OLS and 2SLS point estimates of the impact of family ties on underground economy performed considering the restricted sample of 14 countries with available information on the instrumental variables. OLS results are in line with FE estimates obtained on the full sample (compare columns 1 and 4): independently on the size of the regression sample, both estimators provide a small positive impact of family ties on underground economy (ranging between 0.02 and 0.05 ) suggesting the presence of a downward bias. In column (5), 2SLS estimates confirm this hypothesis since the $b_{1}$ point estimate, after instrumenting the level of family ties, exhibits a much higher magnitude around $1 .{ }^{31}$ Econometric tests on the robustness of our IV analysis are all satisfied especially when family ties are measured in terms of the original variable "importance of the family". In particular: the "underidentification test" and the "weak identification test" show that our instrumental variables are strongly correlated with family ties (similar conclusion has been derived by the results of the first stage regressions results reported in Table 5); finally, the "orveridentification test" does not reject the null hypothesis of exogeneity of the instrumental variables supporting the validity of the IV analysis.

\footnotetext{
${ }^{31}$ Coefficient point estimates must be interpreted in terms of standard deviations of the dependent variables generated by one standard deviation of the regressors.
} 
Table 5. OLS point estimates of the impact of the role of the mother and the role of the father on family ties, first stage regression.

\begin{tabular}{|c|c|c|c|}
\hline & (1) & (2) & (3) \\
\hline Dependent variable & \multicolumn{3}{|c|}{ Importance of family } \\
\hline Role of the mother $(* * * p<0.01, * * p<0.05, * p<0.1)$ & $0.5190^{* * *}$ & $0.3538 * * *$ & \\
\hline Robust standard errors in brackets & [0.049] & [0.038] & \\
\hline Role of the father $\left(* * * p<0.01,{ }^{* *} p<0.05, * p<0.1\right)$ & $-0.2797 * * *$ & & $0.2455^{* * *}$ \\
\hline Robust standard errors in brackets & {$[0.078]$} & & [0.068] \\
\hline R-squared & 0.753 & 0.740 & 0.678 \\
\hline F stat & 58.09 & 49.39 & 33.51 \\
\hline Prob $>F$ & 0.0000 & 0.0000 & 0.0000 \\
\hline
\end{tabular}

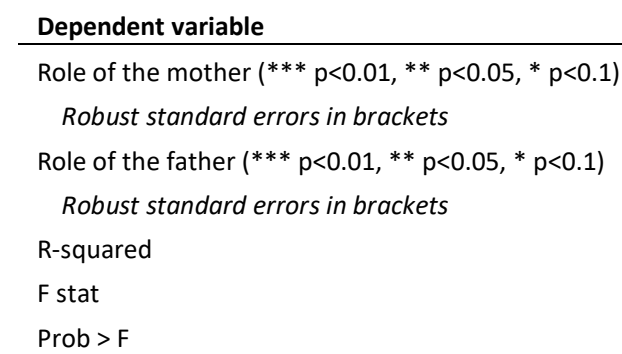

Family ties principal component

\begin{tabular}{|c|c|c|c|}
\hline Observations & 280 & 280 & 280 \\
\hline Constant & Yes & Yes & Yes \\
\hline Control variables & Yes & Yes & Yes \\
\hline Fixed effect & No & No & No \\
\hline Year dummies & Yes & Yes & Yes \\
\hline
\end{tabular}

Columns (4) and (5) of Table 4 show, respectively, the OLS and 2SLS point estimates of the impact of family ties on tax morale performed considering the restricted sample of 14 countries with available information on the instrumental variables. OLS results are in line with FE estimates obtained on the full sample (compare columns 1 and 4): independently on the size of the regression sample, both estimators provide a negative impact of family ties on tax morale (between -0.56 and -0.23). In column (5), after instrumenting the level of family ties, 2SLS point estimates are equal to minus 0.5 and perfectly aligned with FE results suggesting that the bias in our baseline model is very small. ${ }^{32}$ Econometric tests on the robustness of our IV analysis are satisfied: the "underidentification test" and the "weak identification test" show that our instrumental variables are strongly correlated with family ties (similar conclusion has been derived by the results of the first stage regressions results reported in Table 5); finally, the "orveridentification test" does not reject the null hypothesis of exogeneity of the instrumental variables supporting the validity of the IV analysis.

\footnotetext{
${ }^{32}$ Coefficient point estimates must be interpreted in terms of standard deviations of the dependent variables generated by one standard deviation of the regressors.
} 


\section{Conclusions and Policy Implications}

The usual portfolio analysis of tax evasion, based only on a cost-benefits approach, does not successfully explain why do people not comply or decide to behave honestly. Apart from tax inspections, fines and the quality of tax administration, there are many other important variables, both on the social and political economy dimension, that have to be taken into account if one wants to satisfactorily explain the determinants of the shadow economy. Following the recent literature on "social actor" model, which emphasizes the importance of tax morale and social capital to fully understand tax evasion and non-compliance behaviors of taxpayers, in this paper we address the importance of family ties as a determinant of tax morale and the underground economy.

This paper provides the first empirical evidence - to our best knowledge - supporting the argument that family ties are one of the most important determinants of the underground economy, trust and tax morale. To explain the level of the shadow economy, one must consider both the standard fiscal variables (such as tax burden, tax rates, detection policy, fines, tax fairness perception and the other elements that affect tax compliance) but also some social and moral variables, such as the power of the family, tax morale and the degree of trust.

The main policy implications of our results are that the structure of society represents one of the key factors that should be taken into account when designing policies aimed at reducing tax evasion. We believe that, away from any value judgment, it is important to assume a correct balance between trust in the family and trust in public institutions. Moral values shape the quality of public institutions and the intensity of family ties. These values largely affect trust, tax morale the size of the underground economy and the social capital of different nations.

Our analysis shows that the families ties are very important and tend to have evident economic, moral, social and tax implications. The general intermediate structure of a society is weakened when the family is the only source of personal relations and trust. This negatively affects political and civic involvements, and hence tax morale, which in turns produces a higher level of underground economy, reduces tax compliance and ultimately worsens the quality of institutions.

In conclusion, our research shows that to fully address the underground economy and tax evasion, a fully-fledged approach is required. This approach has to be based not only on pecuniary factors, such as the strategy and probability of detention and the size of the penalties, but also on other non-pecuniary factors of tax compliance, such as tax morale, the social capital, the degree of generalized trust and the role of the family. Our paper shows that the role of the family in society and the intensity of family ties are two key determinants in explaining tax morale, the degree of trust and social capital and, in the end, the size of the underground economy. Therefore, any government policies that want to reduce the magnitude of the shadow economy and increase the tax compliance behavior of taxpayers have to define some optimal strategies to implement actions aimed at increasing tax morale, the degree of trust and their complex relationship with family ties. The family is a key core of any society and people behavior. 


\section{References}

Acemoglu, D. and Robinson, J. A. (2011) Why Nation Fails: Origins of Power, Poverty and Prosperity, Crown Publishing, New York.

Alesina, A. and Giuliano, P: (2010) "The Power of the Family", Journal of Economic Growth, vol. 15, May.

Alesina, A. and Giuliano, P. (2011) "Family Ties and Political Participation", Journal of European Economic Association, vol. 9(5).

Allingham, M. J. and Sandmo, A. (1972) "Income Tax Evasion: a Theoretical Analysis", Journal of Public Economics, 1: 323-338

Alm J. and Torgler B. (2004). Estimating the Determinants of Tax Morale. National tax association Tax institute of America, Proceedings of the Ninety-seventh Annual conference on Taxation.

Alm.J. and Torgler, J. (2006) "Cultural differences and tax morale in the United States and in Europe", Journal of Economic Psychology, vol. 27.

Alm J. and Torgler B. (2012). Do Ethics Matter? Tax Compliance and Morality. Working Papers 1207, Tulane University, Department of Economics.

Alm, J., McClelland, G. H. and Schulze, W. D. (1992) "Why do people pay taxes?" Journal of Public Economics, 48(1), 21-38

Alm, J., and McClelland, G. H. (2012) "Tax Morale and Tax Compliance form the Firm's Perspective" Working Papers 1211, Tulane University, Department of Economics.

Alm, J., Martinez-Vasquez, J. and Torgler, B. (2006) "Russian attitude towards paying taxes before, during, and after the transition", International Journal of Social Economics,33(12).

Alm, J. and Martinez-Vasquez, J. (2007) "Tax morale and tax evasion in Latin America", Andrew Young school, International Studies Program, working paper no. 4.

Alm, J. and Gomez, J. (2008) "Social Capital and Tax Morale in Spain", Economic Analysis \& Policy, vol. 38, No. 1, March.

Alm J, Bernasconi M., Laury S., Lee D. and Wallace S. (2016). Culture, Compliance, and Confidentiality: Taxpayer Behavior in the United States and Italy. University Ca' Foscari of Venice, Department of Economics Research Paper Series No. 36.

Alm, J. and Liu, Y. (2018) "Corruption, Taxation, and Tax Evasion", Tulane Economics Working Paper Series, WP 1802, March.

Bachofen, J. (1949) Le madri e la virilità olimpica, Bocca, Milano.

Banfield, E. (1958) The Moral Basis of a Backward Society, The Free Press, Glencoe, Illinois.

Barone, G. and Mocetti, S. (2011) "Tax morale and public spending inefficiency", International Tax and Public Finance

Barzini, L. (1964) The Italians, Touchstone Books, New York

Bernhard, E. (1969) La grande madre mediterranea, in Mitobiografia, Adelphi, Milano.

Bertrand, M. and Schoar, A. (2006) "The Role of Family in Family Firms", Journal of Economic Perspectives, 20(2) 73-96

Bisin, A. and Topa, G. (2002) "Empirical models of cultural transmission", Journal of the European Economic Association

Bisin, A. and Verdier, T. (1998) "On the cultural transmission of preferences for social status", Journal of Public Economics, 70.

Bisin, A. and Verdier, T. (2000) "Beyond the Melting Pot": Cultural Transmission, Marriage and the Evolution of Ethnic and Religious Traits", Quarterly Journal of Economics.

Bisin, A. and Verdier, T. (2010) "The Economics of Cultural Transmission and Socialization", in Handbook of Social Economics, J. Benhabib-A.Bisin-M. Jackson (eds)., Elsevier.

Braithwaite, V. and Wenzel, M. (2008) Integrating explanations of tax evasion and avoidance. In A. Lewis (eds.), The Cambridge Handbook of Psychology and Economic Behavior. Cambridge: Cambridge University Press (pp. 304-331).

Butler, J., Giuliano, P. and Guiso, L.(2009) "The Right Amount of Trust," NBER Working Papers, No. 15344. 
Feld, L., Schmidt, A., and Schneider, F. (2007), Tax Evasion, Black Activities and Deterrence in Germany: An Institutional and Empirical Perspective, Discussion Paper, Department of Economics, University of Heidelberg, Germany.

Feld, L. and Torgler, B. (2007) "Tax morale after the reunification of Germany: Results from a quasi-natural experiment ", Cesifo Working papers, no. 1921.

Frey, B. and Torgler, B. (2007) "Tax morale and conditional cooperation", Journal of Comparative Economics, 35.

Fukuyama, F. (1995), Trust, Free Press Paperbacks, New York.

Fukuyama, Y. F. (1999) The Great Disruption: Human Nature and the Reconstitution of Social Order, Free Press, 1999.

Gambino, A. (1998) Inventario Italiano. Costumi e mentalità di un paese materno, Einaudi, Torino.

Goethe, J. W. (1983) Viaggio in Italia, Mondadori, Milano.

Gramsci, A, (1977) Passato e presente, Roma, Editori Riuniti.

Guicciardini, F. (1983) Considerazione sui "Discorsi" di Machiavelli, in Opere, vol. I Utet, Torino.

Guiso, L., Sapienza, P., and Zingales, L. (2006), "Does Culture Affect Economic Outcomes?" Journal of Economic Perspectives.

Guiso, L., Sapienza, P. and Zingales, L. (2007) "Social Capital as Good Culture," NBER Working Papers 13712,

Guiso, L., Sapienza, P. and Zingales, L.(2010) "Civic Capital as the Missing Link," NBER Working Papers no. 15845.

Halla, M. (2009) "Tax morale and compliance behavior: First evidence on a causal link", IZA Discussion paper, no. 4918.

Heinemann, F.-Schneider, F. (2011) "Religion and the shadow economy," ZEW Discussion Papers 11-038, ZEW - Zentrum für Europäische Wirtschaftsforschung/Center for European Economic Research.

Horodnic I. A. (2018) "Tax morale and institutional theory: a systematic review. International Journal of Sociology and Social Policy. Vol. 38 No. 9/10 pp. 868-886

Konig, N.-Schuknecht, L. (2018) "The Role of Government and Trust in the Market Economy", Cesifo Working Papers, 6997, April.

Lago-Penas, I. and Lago-Penas, S. (2010) "The determinant of tax morale in comparative perspective: Evidence from European countries", European Journal of Political Economy, 26.

La Porta, R., Lopez-de-Silanes, F. and Shleifer, A. (2007) "The Economic Consequences of Legal Origins," NBER Working Papers no. 13608.

Leopardi. G. (1991) Discorso sopra lo stato presente dei costumi degli Italiani, Feltrinelli, Milano.

Lewis, A.-Carrera, S.-Cullis, J.-Jones, P. (2009) "Individual, cognitive and cultural differences in tax compliance: UK and Italy compared", Journal of Economic Psychology, 30.

Ljunge, M. 2013. "Social Capital and the Family: Evidence that Strong Family Ties Cultivate Civic Virtues," Working Paper Series 967, Research Institute of Industrial Economics.

Medina L. and Schneider, F. (2017) "Shadow Economies around the World: New Results for 158 Countries over 1991-2015". Department of Economics Johannes Kepler University of Linz, Working Paper No. 1710.

North, D. (1990) Institutions, institutional change, and economic performance, Cambridge, Cambridge University Press.

Putnam, R. (1993) Making Democracy Work, Princeton University Press, Princeton.

Putnam, R. (2000) Bowling Alone, Princeton University Press, Princeton.

Richardson, G. (2008) "The relationship between culture and tax evasion across countries: additional evidence and extensions", Journal of International Accounting, Auditing and taxation, 17.

Salvemini, G. (1966) La mentalità degli Italiani, 1928 in Opere, vol. VI/2, Feltrinelli, Milano,1966.

Schneider, F. (2005) "Shadow economies around the world: What do we really know?", European Journal of Political Economy, 21.

Schneider F.,-Buehn, A.,--Montenegro, C.E. (2010) "Shadow Economies All over the World: New Estimates for 162 Countries from 1999 to 2007," Working Papers wp322, University of Chile, Department of Economics.

Schneider, F.-Enste, D. (2000) "Shadow economies: Size, causes and consequences", Journal of Economic Literature, 21. 
Schneider, F.-Enste, D. (2002) The shadow economies. An international survey, Cambridge, Cambridge University Press.

Simone, R. (2005) Il paese del pressappoco, Milano, Garzanti.

Slemrod, J.,-Yitzhaki, S. (2002) "Tax avoidance, evasion, and administration," Handbook of Public Economics, in A. J. Auerbach \& M. Feldstein (ed.), Handbook of Public Economics, edition 1, volume 3, pages 14231470 Elsevier.

Stendhal (1956) Rome, Naples et Florence en 1817, Suivi de l'Italie en 1818, Le Divan, Paris.

Tabellini, G. (2008) "Institutions and Culture", Journal of the European Economic Association Papers and Proceedings,6 (2-3).

Tabellini, G. (2010) "Culture and institutions: economic development in the regions of Europe", Journal of the European Economic Association

Torgler, B. (2003) "Tax morale and tax compliance: evidence from the United States", WWZ Discussion Paper, no. 02.

Torgler, B. (2004) "Tax morale in Asian countries", Journal of Asian Economics,15.

Torgler, B. (2005) "Tax morale in Latin America", Public Choice, 122(1).

Torgler, B. (2006) "The importance of faith: tax morale and religiosity", Journal of Economic Behavior and Organizations, 61.

Torgler, B. (2007) Tax compliance and tax morale: A theoretical and empirical analysis, Cheltenham, UK, Edward Elgar.

Torgler, B.-Schenider F. (2006) "What shapes attitudes toward paying taxes? Evidence form Multicultural European Countries", IZA Discussion paper, no. 2117.

Torgler, B.-Schenider F. (2009) "The impact of tax morale and institutional quality on the shadow economy", Journal of Economic Psychology, 30.

Tsakumis, G.-Curatola, A.-Porcano, T. (2007) "The relation between national cultural dimensions and tax evasion", Journal of International Accounting, Auditing and Taxation,16, 131-147.

Turiello, P. (1980) Governo e governati in Italia, Einaudi, Torino.

Williams C. C. and Horodnic I. A. (2016). Evaluating the policy approaches for tackling undeclared work in the European Union. Environmental and Planning C Government and Policy. 35(5).

Williams C. C. and Krasniqi B. A. (2017). Evaluating the individual and country level variations in tax morale: Evidence from 35 Eurasian countries. Journal of Economic Studies 44(2). 